\title{
Chinese Students and Customers Purchasing Demands: A 10-year Systematic Review on Luxury Education
}

\author{
Teeranart Chaiinkam, George P. Zhang \\ Gemological Institute \\ China University of Geosciences \\ Wuhan, P.R. China \\ tera.worldsapphire@gmail.com
}

\author{
Chinun Boonroungrut \\ Vongchavalitkul University \\ Nakhon Ratchasima, Thailand
}

\author{
Wulan Patria Saroinsong \\ Department of Early Childhood Education \\ Universitas Negeri Surabaya \\ Surabaya, Indonesia
}

\begin{abstract}
The measurements of Chinese demand on purchasing luxury goods are varying depending on the design implemented by researchers in the previous luxury studies. This review aims to explore empirical implications by identifying the key demands that influence Chinese students or consumers' attitudes towards purchasing luxury goods. Full-text articles related to luxury and published in Science Direct and EBSCO databases during 2009 - 2018 were collected. Among a total of 480 articles worldwide, the systematic review under PRISMA guideline included 12 articles into this study which represented clearly on Chinese luxury purchasing demands. The findings showed that researchers tended to develop their own measurements. The rating scale method was found in almost all of those studies. Shanghai was the top destination in conducting the research. Most researchers categorized the measurement dimensions following Branding, Price \& Values, Design \& Uniqueness, and Self-evaluation respectively. This paper will broaden the research pertaining to luxury purchasing demand measurement, and help saving time for future research which shares advantage to students studying in business and luxury marketing education.
\end{abstract}

Keywords-Chinese consumers; demand; luxury; measure; purchasing

\section{INTRODUCTION}

Since the economic reforms in 1978, China has become one of the world's manufacturing hubs in the secondary sector including construction and comprising industries. It has been represented by the largest 40-year GDP growth under this reforming policy. Over 800 million people have been lifted out of poverty and the country has achieved upper middle-income status (focus-economics.com). China has been one of the world's largest population of wealth households since the last decade [1]. The growth was resulted from country's changing economy and the rise of middle class and upper middle class, raising the purchasing power and increasing a willing to pay more for higher quality, brand names, and differentiated features [2]. According to the Boston Consulting Group, the global luxury goods market has significantly benefited from the economic growth since 2001, especially in the new market including China, Russia, and India [3]. In China today, luxury goods can be found everywhere with ease to purchase and acquire the quality services, particularly in the first and secondtier cities such as Beijing, Shanghai, Guangzhou and Hong Kong [4,5]. Since 2017, China has become the world's largest luxury market where it's growth has been expected to increase by approximately 12 percent. Chinese millennials from the middle-class consumers were the new target group, whose large contribution was made to the market growth. A single child was armed with an increasing family wealthy. Purchasing fashion jewelry, cosmetics, handbags and receiving services relied more on luxury brands and occurred more frequently $[6,7]$. Notably, since the end of the past century, woman luxury products in China have raised a strong brand consciousness, prestige, and prosperity symbol. Chinese consumers have remarkably shown better knowledge of the existing brands [8].

The concept of luxury evokes an individual's power and image of wealthy lives. It could be regarded as an ordinary of extraordinary people [9]. In the history of elite society, luxury could be found in many aspects of human activities, particularly in the form of construction creation, for example, pyramids, ancient emperor's tombs and pagodas through the sacrifice of wealth [10]. Luxury has been referred to as one of our aristocratic societies until the present time. Nowadays, luxury establishes social stratification in some countries where itself has priory never existed $[11,12]$. In defining luxury within a consumer society, Mortelmans [13] pointed out that it could be presented in all times and cultures. The term of luxury could also be conceptualized in a narrower sense as a symbol of extra value with higher quality and price when comparing 
among the similar products. In a wider sense, an implication of luxury was used to differentiate the social class of people, although those meaning was understood merely within certain groups. Since the beginning of the 21 st century, it is obvious that luxury has played a significant role in identifying class of products and services.

Luxury has an intangible character that indicates distinctive senses of taste and class; however, the decision to point out what is luxury or higher than ordinary depends on perspectives. It can be categorized into these relativities: (1) Regional relativity refers to an available resource on the necessity-luxury continuum. (2) Temporal relativity refers to perception which changes over time on the availability and desirability. (3) Economic relativity refers to individuals' differences in the perception of luxuriousness. (4) Cultural relativity refers to desirability of resources to people. It may be different in consideration of luxurious perception within different culture if it comes from the same resource. And (5) Situational relativity refers to the same resource could be differently classified as luxurious or not depending on such circumstances [14-17].

Consumer purchase intention refers to a willingness to buy any products or services. It can be regarded as a primary marketing prediction input for determining the impact of consumers' purchasing behaviors including the demand for new products [18]. Notably, the purchase intention can be applied as a representative of consumers' financial, functional, individual or social values [19].

A number of researchers pointed out interesting findings that some Chinese consumers purchased luxury goods on purposes of manifesting their economic status, and securing their social recognition due to their culture values the shift in the status hierarchy [20]. So to speak that luxury could be broadly recognized as a symbol of power and wealthiness. Nowadays, most luxury goods companies realize that China is a peculiar and complex market with an extreme vastness of size, meanwhile, has a low level of brand loyalty and has significant differences in regional retail infrastructure [21]. However, the previous studies with empirical data on the need for luxury purchasing are limited to a few variables. This review, thus, will be of great benefit to addressing how the prior researchers had done in studying Chinese consumer demand on purchasing luxury goods.

\section{METHOD}

\section{A. Search Strategies and Data Retrieval}

The data was collected by exploring all dimensions regarding luxury given by the prior researchers, applied to researches among Chinese consumers, and published between 2009 and 2018. Under the Preferred Reporting Items for Systematic Reviews and Meta-analyses guidelines (PRISMA), this study potentially showed an evidence-based minimum set for reporting used as a basis in reviewing [22]. A 5-stage process was performed: 1) database searching, 2) articles identification and initial abstract reviewing, 3) exclusion and inclusion from criteria, 4) full-text retrieval, and 5) analysis [23-24].

\section{B. Selection Criteria and Data Extraction}

Two main electronic databases regarding behavioral science, business, and management studies were ScienceDirect and EBSCO (all publications released online between 2018 and 2019). The lists of studies and relevant articles related to Chinese and luxury with the terms of consumer or buyer were selected in the screening process. The specific keywords were further looked up in the Boolean search by using the terms as 'Chinese' and 'luxury' and 'consumer' or 'consumption'. The final applied keywords were "Chinese" or "China" with "luxury" or "luxury consumer" or "luxury customer" or "luxury buyer" or "luxury purchase" or "luxury purchaser" or "luxury shopper" or "luxury user" and were searched from both databases. A systematic review, meta-analysis study, and articles published in any languages other than English were excluded. English publications with luxury content related to marketing, management and business studies as well as organizational psychology were targeted. To categorize the researchers' studied dimension of Chinese luxury consumers, this review retrieved only the articles which were identified clearly with either Chinese and consumer or related keywords in their titles and abstracts. The cut-out keywords then were used in the screening process. Those articles without supporting literature were also excluded. The abstracts and fulltext articles were then screened and reviewed respectively in order to select all eligibility. Each presented dimension in those eligible articles was classified by agreement between the authors following the cross-checking method. Any disagreed and unmatched details were resolved by discussion from all authors. After that a narrative qualitative synthesis was conducted.

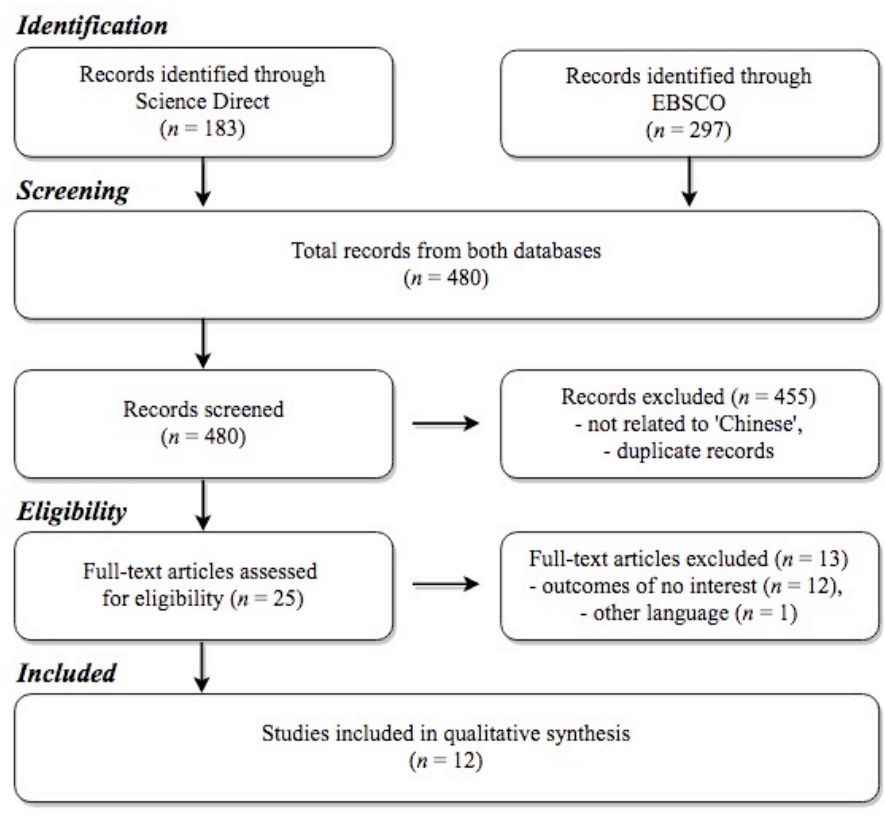

Fig. 1. Prisma guideline statement of the included studies [22]

\section{RESUltS AND DISCUSSION}

A total of 480 articles related to luxury consumers was found in both databases during 10 years of publication, 
between 2009 and 2018 as shown in Figure 1. Those articles were scoped to completed academic-referencing articles with searching keywords 'Chinese' or 'China' in luxury purchase intention. Twenty-five articles specified 'Chinese' clearly in their titles and abstracts. Inclusion and Exclusion criteria were evaluated with full-text assessed. Twelve articles were excluded because they were irrelevant to the study, for example, one of them was published in another language.

Among all those 12 articles, 4 articles were published in the Journal of Business Research. Interestingly, most measurements were designed by researchers themselves based on a wide range of luxury and consumer concepts. A few measurements from previous studies were modified in order to develop some new ones. Two sample groups were university students and general consumers. Not only was the simple random sampling method found in selecting those sample groups, but also the snowball sampling method. The rating scale type of measurement was implemented in all studies. Shanghai was the top destination where researchers conducted their study in the field of luxury consumers in China. Apart from Shanghai, the first-tier cities such as Beijing and Guangzhou were other targeted destinations. Remarkably, the majority of authors, who were interested in exploring luxury goods consumption in China, were not Chinese.

a set of 17 dimensions was extracted. Branding and Price \& Values were the most interesting dimensions towards purchasing luxury goods in researchers' perspective. In detail, the first-dimension group (Branding and Price \& Values) described the perception of the individual to how luxury branding makes the brand itself luxurious. The second group pointed to Design \& Uniqueness and Self-evaluation. Design \& Uniqueness showed the differences between unique and mass product design. They described branding as well as customer perception towards an individual's self, innovation, and fashion identity. This dimension might make people remember the uniqueness from both branding and perception in designing. Self-evaluation, meanwhile, described how an individual considers oneself whether or not he/she deserves to possess luxury goods. It also explained how an individual estimates his/her ability to obtain those products. The third-dimension group referred to social-related factors, which consisted of Materialism, Purchase Intention, Social-function Influence, and Normative Influence. According to the fundamental concept of this dimension, luxury showed the relationship between Materialism and physical comfort. Apart from the above 3 dimension groups, Information \& Advertising, Privilege Attitudes, Cultural Factors, Network of Relationship, Country of Origin, Celebrity Endorsement, Practical Usage, Time Specialty \& Gift and Warranty were also reviewed but only by a few researchers.

This latest systematic review indicated a variety of elements that the researchers previously used to measure Chinese consumer demand on purchasing luxury goods. The findings were gathered from the limitation of research methods during the past 10 years (up to 2018). According to the findings, several factors, which researchers were interested in and were used to measure Chinese consumer demands on purchasing luxury goods, were relevant to the global concepts and perceptions of luxury consumers. These factors described that luxury evoked the exclusivity, high brand awareness, brand quality and brand identity [36,37]. For examples, Beverland [38] categorized a luxury brand model with these following dimensions: product integrity, value-driven emergence, culture, history, marketing, and endorsement. Similarly, a PRECON scale of Deeter-Schmelz, Moore [39] pointed out 5 factors in motivating the consumption of luxury goods as follows: image, quality, fashion, store atmosphere, and patron status. Zhang \& Kim [7] concluded 5 factors as follows: brand consciousness, materialism, social comparison, fashion innovation, and fashion involvement. It was interesting to note that store atmosphere was one of the factors that found none in those databases, therefore, it will be useful to study more in the future.

Although the researchers in prior studies considered luxury based on the viewpoint of Western cultures [40], this review reflected the consistency between Chinese and worldwide consumers such as in Bosnia, France, Russia and Australia [41]. It was because the consumers wished to fulfill their needs with luxury products, consequently, those products might be used on purpose to impress other people and position the owners in any certain group they wish to belong. It was notable that materialism among Chinese people had developed within a wealthy family whose children would be treated with money for their happiness. This phenomenon could not be judged whether it was right or wrong since those parents had experienced and suffered from poverty before in their childhood during the Cultural Revolution and Economic Reforms [7]. As a result, purchasing luxury goods in Chinese people's viewpoint was not just for self-satisfaction but to earn acceptance among the family members.

This review explored both theoretical and empirical implications by identifying the key demands that influence Chinese consumers' attitudes towards purchasing luxury goods. Branding and Price \& Values were the first factors which were interested in by many researchers and found in many studies that compared Chinese consumers with consumers from other countries such as France, India, Italy, Japan, Russia and the U.S. [25, 42]. These factors also seemed to be the first dimension that had an impact on design and advertising. The sample group was mostly selected from the Chinese middle-class and upper-class consumers, although some of them were students. The studies reflected consumer satisfaction through taste and social status that finally would encourage customer loyalty to luxury brands. Chinese middleclass consumers were now more confident and independentminded as well as were determined to manifest such independence upon their consumption. They, however, had different attitudes towards luxury goods and purchasing luxury goods [43]. As mentioned above, cultural values had a considerable influence on purchasing luxury goods among Chinese consumers, especially when speaking of social values [44]; nevertheless, several studies have not yet explored these factors. A study of Shukla, Singh [45], for example, analyzed only functional value by comparing between Chinese, Indian and Indonesian consumers.

Price was one of the factors that were taken into consideration before purchasing luxury goods. Compared to Italy, the findings of Godey, Pederzoli [42] indicated that 
displaying the product price induced sensitivity in decision making among Japanese and Chinese consumers. Astmon [46] found empirical evidence that more than half of luxury consumers checked price and details online. In addition, 2 out of 5 Chinese consumers from mainland China were aware that the price of several luxury products was 20 percent higher than sold in Hong Kong in 2008. It was probably because these consumers had more opportunity to travel aboard so they could compare the price between both countries.

Price of luxury goods generally reflected their identity, quality, heritage and exclusivity [12]. Price \& Values factor, as a result, had an influence on middle-class consumers around the world in making a decision before purchasing; not only in China but also in most developing countries. Particularly, an increasingly growing of this consumer group enabled them to possess the most purchasing power in a luxury business in China. Developing marketing strategies to meet their certain needs was, therefore, a challenging task. The growing of luxury market, a higher price of luxury products and a higher demand of consumers might inevitably affect the market growth of counterfeit goods due to China was wellknown as a huge manufacturer and exporter in this business [47]. In this case, it could represent the luxury consumers' attitudes on how they valued luxury goods from their consumption of counterfeit goods.

The studies of several factors that had an influence on purchasing luxury goods among Asian consumers, such as in Iran, Indonesia and Thailand, indicated that these same factors could also be used to measure consumer purchase intention in other countries. A number of studies used the Theory of Planned Behavior, which includes Attitudes, Subjective Norm, and Perceived Behavioral Control to gain an insight into the luxury students and consumers' behavior [48-50].

\section{CONCLUSION}

There are 3 considerations should be taken in proceeding the latest findings: 1) the data was retrieved systematically only from two main e-databases which were ScienceDirect and EBSCO. Comparing with other sources, like Emerald and Springers and unpublished works, might help to see the overall picture more clearly and reduce publication bias. 2) The searching keywords covered only words or phrases related to luxury purchasing demand. And 3 ) the data was collected only from English articles since other studies were most likely published in Chinese and stored in Chinese databases. It could be the light for future research to bridge this gap of knowledge.

In Conclusion, this review found that factors to measure luxury purchase intention of Chinese consumers were varying. Chinese students and consumers were the target population. Shanghai was the top destination in conducting the study following with Beijing and Guangzhou. In categorizing the dimensions, Branding, Prices \& Values, Design \& Uniqueness, and Self-Evaluation were respectively the most interesting factors in measuring the purchasing demand of Chinese luxury consumers. These findings could be one of the guidelines that researchers use to select the factors in order to broaden their study about Chinese luxury students and consumers demand in the future.

\section{REFERENCES}

[1] S. Atran, J. Ginges, "Religious and sacred imperatives in human conflict.” Sci., vol. 336, no. 6, pp. 855 - 857, 2012.

[2] K. Song, and A. Cui, "Marketing-Understanding China's Middle ClassMarketers should recognize the diversity among China's middle class consumers and target key segments with appropriate strategies," China Bus. Rev., vol. 36, no. 1, pp. 38 - 48, 2009.

[3] T.-Y Eng, and J. Bogaert, "Psychological and cultural insights into consumption of luxury western brands in India," J. Consum. Behav., vol. 9, no. 1, pp. $55-75,2010$.

[4] Y. Atsmon, and V. Dixit, "Understanding China's wealthy," McKinsey q, vol. 4, pp. 1 - 10, 2009.

[5] M. Chevalier, and P. Lu, Luxury China: Market opportunities and potential: John Wiley \& Sons, 2009.

[6] A. Chen, and N. Peng, "Examining Chinese consumers' luxury hotel staying behavior," Int. J. Hosp. Manag., vol. 39, no. 1, pp. 53 - 56, 2014

[7] B. Zhang, and J. Kim, "Luxury fashion consumption in China: Factors affecting attitude and purchase intent," J. Retail. Consum. Serv., vol. 20, no. 1 , pp. $68-79,2013$.

[8] S. H. Tai, and J. Tam, "A lifestyle analysis of female consumers in greater China," Psychol. Mark., vol. 14, no. 3, pp. 287-307, 1997.

[9] J. Kapferer, “Abundant rarity: The key to luxury growth," Bus. Horiz., vol. 55, no. 5, pp. 453-462, 2012.

[10] J. Castarède, "Luxe et civilisations," Paris: Eyrolles, 2008

[11] J. M. Podolny. Introduction to Status Signals: A Sociological Study of Market Competition. Princeton University Press, 2008.

[12] J. N. Kapferer, and V. Bastien. "The specificity of luxury management: Turning marketing upside down," J. Brand Manag., vol. 16, no. 5, pp. 311-322, 2009.

[13] D. Mortelmans. "Sign values in processes of distinction: The concept of luxury,” Semiotica, vol. 157, no. 1, pp. 497-520, 2005.

[14] K. Heine. The concept of luxury brands, EMLYON Business School, pp. 2193-1208, 2012.

[15] S. Kemp. "Perceiving luxury and necessity," J. Econ. Psychol., vol. 19, no. 5, pp. 591-606, 1998.

[16] K. Heine, \& M. Phan. "Trading-up mass-market goods to luxury products," Aus. Mark. J., vol. 19, no. 2, pp. 108-114, 2011.

[17] J. Goody. "From misery to luxury," J. Soc. Sci., vol. 45, no. 3, pp. 341348, 2006.

[18] V. J. F. Morwitz, \& T. I. Consumers' purchase intentions and their behavior. Found. Trend. Mark., vol. 7, no. 3, pp. 181-230, 2014.

[19] K. Wiedmann, N. Hennigs, \& A. Siebels. "Measuring consumers' luxury value perception: a cross-cultural framework," Acad. Mark. Stud. J., vol. 12, no. 7, 2007.

[20] L. Gao, M. J. Norton, Z. Zhang, \& T. Kin-man. "Potential niche markets for luxury fashion goods in China," J. Fashion Stud., vol. 13, no. 4, pp. 514-526, 2009.

[21] Zhan, L., \& He, Y. "Understanding luxury consumption in China: Consumer perceptions of best-known brands," J.Bus.Res., vol. 65, no. 10, pp. 1452-1460, 2012.

[22] Moher, D., Liberati, A., Tetzlaff, J., \& Altman, D. "Preferred reporting items for systematic reviews and meta-analyses: the PRISMA statement," PLoS MED., vol. 8, no. 5, pp. 336-341, 2009.

[23] Beller, E. M., Glasziou, P. P., Altman, D. G., Hopewell, S., Bastian, H., Chalmers, I., Group, P. f. A. "PRISMA for abstracts: reporting systematic reviews in journal and conference abstracts," PLOS MED, vol. 10, no. 4, e1001419, 2013.

[24] Tsai, S. "Impact of personal orientation on luxury-brand purchase value: An international investigation,” Int.J.Mark.Res., vol. 47, no. 4, pp. 427 452, 2005.

[25] Godey, B., Pederzoli, D., Aiello, G., Donvito, R., Chan, P., Oh, H., Weitz, B. "Brand and country-of-origin effect on consumers' decision to purchase luxury products," J.Bus.Res., vol. 65, no. 10, pp. 1461-1470, 2012 . 
[26] Li, G., Li, G., \& Kambele, Z. "Luxury fashion brand consumers in China: Perceived value, fashion lifestyle, and willingness to pay," J.Bus.Res., vol. 65, no. 10, pp. 1516-1522, 2012.

[27] Zhan, L., \& He, Y. "Understanding luxury consumption in China: Consumer perceptions of best-known brands," J.Bus.Res., vol. 65, no. 10, pp. 1452-1460, 2012.

[28] Bian, Q., \& Forsythe, S. "Purchase intention for luxury brands: A cross cultural comparison," J.Bus.Res., vol. 65, no. 10, pp. 1443-1451, 2012.

[29] Wang, Y., Sun, S., \& Song, Y. "Chinese luxury consumers: Motivation, attitude and behavior," J.Promot.Manag., vol. 17, no. 3, pp. 345-359, 2011

[30] Jung, J., \& Shen, D. "Brand equity of luxury fashion brands among Chinese and US young female consumers," J.East-West Bus., vol. 17, no. 1, pp. 48-69, 2011

[31] Tsai, W. S., Yang, Q., \& Liu, Y. "Young Chinese consumers' snob and bandwagon luxury consumption preferences," J.Int. Consum. Mark., vol. 25, no. 5, pp. 290-304, 2013.

[32] Wang, Y., \& Song, Y. "Counterfeiting: Friend or foe of luxury brands? An examination of Chinese consumers' attitudes toward counterfeit luxury brands," J. Global Market., vol. 26, no. 4, pp. 173-187, 2013.

[33] Chen, J., \& Kim, S. “A comparison of Chinese consumers' intentions to purchase luxury fashion brands for self-use and for gifts," J.Int. Consum. Mark., vol. 25, no. 1, pp. 29-44, 2013.

[34] Chen, Y.-Q., Zhu, H., Le, M., Wu, Y.-Z. "The effect of face consciousness on consumption of counterfeit luxury goods," SOC BEHAV PERSONAL., vol. 42, no. 6, pp. 1007-1014, 2014.

[35] Liu, L., Parganas, P., Chadwick, S., Anagnostopoulos, C., Parganas, P. "Sports Celebrity Endorsements of Luxury Brands: The Case of Chinese Consumers," I.J.S.Ma.R.T., vol. 25, pp. 45-68, 2016.

[36] Phau, I., Prendergast, G., \& Chuen, L. "Profiling brand-piracy-prone consumers: an exploratory study in Hong Kong's clothing industry," $J$. Fash. Mark. Manag., vol. 5, no. 1, pp. 45-55, 2001.

[37] Phau, I., \& Prendergast, G. "Consuming luxury brands: the relevance of the 'rarity principle'," J. Brand Manag., vol. 8, no. 2, pp. 122-138, 2000.

[38] Beverland, M. "Uncovering "theories-in-use": building luxury wine brands,” Eur. J. Mark., vol. 38, no. 3/4, pp. 446-466, 2004
[39] Deeter-Schmelz, Moore, J., \& Goebel, D. "Prestige clothing shopping by consumers: a confirmatory assessment and refinement of the PRECON scale with managerial implications," J. Market. Theor. Pract., vol. 8, no. 4, pp. 43-58, 2000.

[40] Summers, T., Belleau, B., \& Xu, Y. "Predicting purchase intention of a controversial luxury apparel product," J. Fash. Mark. Manag., vol. 10, no. 4, pp. 405-419, 2006.

[41] Husic, M., \& Cicic, M. "Luxury consumption factors," J. Fash. Mark. Manag., vol. 13, no. 2, pp. 231-245, 2009.

[42] Jain S, Khan M, Mishra S. "Understanding consumer behavior regarding luxury fashion goods in India based on the theory of planned behavior," J.Asia Bus. Stud., vol. 11, no. 1, pp. 4-21, 2017.

[43] Lingjing, Z., \& Yanqun, H. "Understanding luxury consumption in China: Consumer perceptions of best-known brands," J. Bus. Res., vol. 65 , no. 10, pp. 1452-1460, 2012

[44] Li, J., Zhang, X., \& Sun, G. "Effects of "face" consciousness on status consumption among Chinese consumers: Perceived social value as a mediator," Psychol. Rep., vol. 116, no. 1, pp. 280-291, 2015.

[45] Shukla, P., Singh, J., \& Banerjee, M. "They are not all same: variations in Asian consumers' value perceptions of luxury brands," Mark. Lett., vol. 26, no. 3, pp. 265-278, 2015.

[46] Atsmon, Y., Dixit, V., \& Wu, C. "Tapping China's luxury-goods market," McKinsey Q., vol. 2, pp. 1-5, 2011.

[47] Bian, \& Veloutsou, C. "Consumers' attitudes regarding non-deceptive counterfeit brands in the UK and China," In Advances Chinese Brand Management pp. 331-350, 2017.

[48] Salehzadeh, R., \& Pool, J. K. "Brand attitude and perceived value and purchase intention toward global luxury brands," J.Int. Consum. Mark. vol. 29, no. 2, pp. 74-82, 2017.

[49] Sari, D., \& Kusuma, B. "Does luxury brand perception matter in purchase intention? A comparison between a Japanese brand and a German brand.." AMJ., vol. 5, no. 1, pp. 50-53, 2014.

[50] Boonroungrut, \& Huang. "The Theory of Planned Behavior (TPB) \& Transtheoretical Model (TTM): A systematic Review on Combining Two Behavioral Change Theories in Research," J. Pub. Heal. Dev., vol. 16, no.1, 2018. 